\title{
REVIEW OF THE CURRENT INITIATIVES FOR CARBON DIOXIDE UTILIZATION TECHNOLOGIES IN EUROPE AND THE PROSPECTS FOR ROMANIA - PART I
}

\author{
Athanasios Tiliakos ${ }^{1,2^{*}}$, Adriana Marinoiu ${ }^{1 *}$ \\ ${ }^{I}$ National Research and Development Institute for Cryogenics and Isotopic Technologies - ICSI Rm. \\ Valcea, 4 Uzinei Street, P.O. Box Râureni 7, 240050, Rm. Valcea, Romania \\ ${ }^{2}$ National Research and Development Institute for Laser, Plasma and Radiation Physics - INFLPR \\ București, 409 Atomiştilor Street, P.O. Box MG-36, 077125, Măgurele, Ilfov, România
}

\begin{abstract}
:
Carbon Capture, Utilization, and Storage (CCUS) technologies comprise a set of proposed technological solutions (i.e. methods, measures, implementations, and policies) that seek to trap carbon dioxide - the main form of carbon carrier molecule responsible for the greenhouse effect, originating from human economic activities, and destabilizing the planetary climate before its release into the atmosphere. The aim and function of CCUS manifest as either preventive measures that lock carbon dioxide permanently underground or in other suitable media (Carbon Capture and Storage, CCS), or as redirecting processes that feed it back to augmented industrial cycles for manufacturing products with positive financial impacts (Carbon Dioxide Utilization, CDU). Following recent initiatives at the European level and in view of the larger picture unfolding at the global theater, this digest review aims to deliver the main points, considerations, and dynamics that drive and formulate modern CCUS initiatives, focusing more on the recently surfaced CDU front. We will explore proposed pathways for materializing CDU by looking carefully on unfolding examples from such global and European arenas. We will then scrutinize plausible scenarios for transposing CDU to Romania to ask - and hopefully answer - the right questions as to how such scenarios can materialize.
\end{abstract}

\section{Article info:}

Received 14 May 2021

Received in revised form

12 July 2021

Accepted 15 July 2021

Available online 9 November 2021

Keywords:

Carbon Dioxide Utilization (CDU),

Carbon Capture \& Storage (CCS)

How to cite: Tiliakos, A., Marinoiu, A., (2021). Review of the current initiatives for Carbon Dioxide Utilization technologies in Europe and the prospects for Romania - Part I. Smart Energy and Sustainable Research, 24(2), 73-88, https://doi.org/10.46390/j.smensuen.24221.440

\footnotetext{
*Corresponding authors: Athanasios Tiliakos,E-mail: thanos.tiliakos@icsi.ro,thanos.tiliakos@inflpr.ro; andAdriana Marinoiu, E-mail: adriana.marinoiu@icsi.ro
} 


\section{INTRODUCTION}

Carbon Capture, Utilization, and Storage (CCUS) technologies comprise a set of proposed technological solutions (i.e. methods, measures, implementations, and policies) that seek to trap carbon dioxide - the main form of carbon carrier molecule responsible for the greenhouse effect, originating from human economic activities, and destabilizing the planetary climate - before its release into the atmosphere. The aims and functions of CCUS manifest as either Carbon Capture and Storage (CCS), i.e. preventive measures that lock carbon dioxide permanently underground or in other suitable media, or as Carbon Dioxide Utilization (CDU), i.e. redirecting processes that feed it back to augmented industrial cycles for manufacturing products with positive financial impacts (Fig. 1).

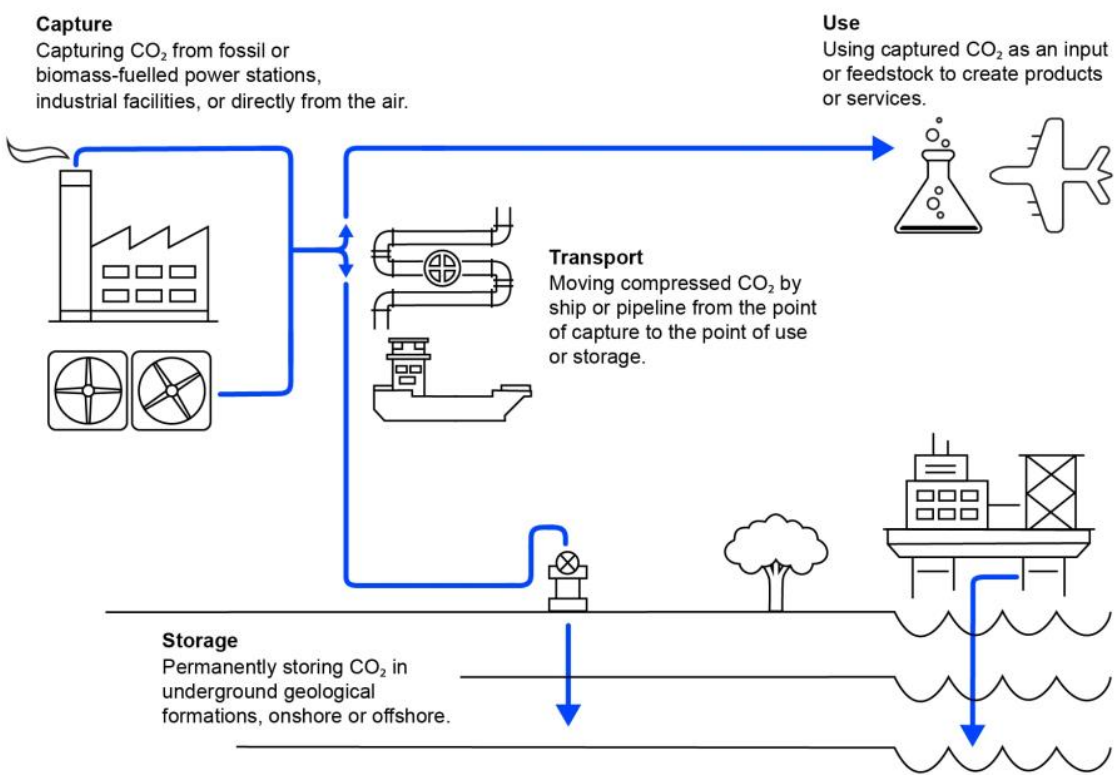

Figure 1. Synergy between CCS and CDU processes within an integrated CCUS scheme.

Understanding when a technology is ripe for implementation - it has transitioned into financial viability, externalities have been mitigated, or framework conditions dictate its necessity - often comes by observing clear and tangible signals propagating within the cultural mainstream. Such a case happened recently in the first semester of 2021, when American business magnate Elon Musk, the CEO/CTO and founder of high-tech companies such as SpaceX, Tesla, Neuralink, and OpenAI, launched the XPRIZE Carbon Removal contest, a $\$ 100 \mathrm{M}$ competition and the largest incentive prize aimed at fighting climate change and rebalancing the planetary carbon cycle in history, its incentive given as: "tackling the biggest threat facing humanity" (Musk Foundation, 2021). The announcement of the competition guidelines, aptly placed on Earth Day, April $22^{\text {nd }} 2021$, outlined its necessity by giving the backdrop of our current climate conundrum:

"The International Panel on Climate Change (IPCC) estimates that we may need to remove as much as 10 billion tons per year by 2050, including 2.5 gigatons of $\mathrm{CO}_{2}$ per year by 2030 to avoid the worst effects of climate change. For humanity to reach the Paris Agreement's goal of limiting the Earth's temperature rise to no more than $1.5^{\circ} \mathrm{C}$ of preindustrial levels, or even $2^{\circ} \mathrm{C}$, we need bold, radical tech innovation and scale up that goes beyond limiting $\mathrm{CO}_{2}$ emissions, but actually removes $\mathrm{CO}_{2}$ already in the air and oceans. If 
humanity continues on a business-as-usual path, the global average temperature could increase $6^{\circ} \mathrm{C}$ by the year 2100." (Eggleston et al., 2006; Bernstein et al., 2007; Pachauri and Reisinger, 2007; Musk Foundation, 2021).

The above serving as a basic summary, we focus on the words of Peter $\mathrm{H}$. Diamandis, founder and executive chairman of the contest: "We hope to push this critical field forward in the same way that the Ansari XPRIZE moved commercial spaceflight... The day before something is truly a breakthrough, it's a crazy idea..." (Musk Foundation, 2021). His introduction highlights the key point behind all such frontier technologies: unless they receive support in the form of subsidies and policies, they are very difficult to take off, as their implementation clashes with the preconceptions about what is viable or achievable in the profit-driven mindset, which tends to masquerade as conventional wisdom.

Sabine Hossenfelder, theoretical physicist and popular science writer, placed the XPRIZE contest in context, and elucidated the general case for CCS technologies. Restating the aim of the contest "to produce a working carbon removal prototype that can be rigorously validated and that is capable of removing at least 1 ton per day, with the carbon being locked up for at least 100 years", Hossenfelder underlined the main metric of XPRIZE as the cost per ton of removed carbon dioxide (Hossenfelder, 2021). Reviewing available CCS technologies, the distinction evolves between methods that rely on enhancing natural removal processes (e.g. ocean fertilization and tree-planting for natural carbon sinks) vs. the application of technologies for permanent carbon removal (e.g. waste pyrolysis for biochar production, enhanced weathering and mineralization, direct air capture, seawater carbon extraction) vs. in situ CCS (i.e. binding $\mathrm{CO}_{2}$ directly at the release point of industrial facilities) (Table 1). In any case, the recurring point of interest is the importance of cost as the critical factor for implementing CCS technologies: economic viability is paramount (Eggleston et al., 2006; Bernstein et al., 2007; Pachauri and Reisinger, 2007; Rao and Chandur, 2021).

Table 1. CCS technologies, associated challenges, and projected costs (Hossenfelder, 2021).

\begin{tabular}{lcr}
\hline Method & Challenge & Cost $\left[\$ / \mathrm{tCO}_{2}\right]$ \\
\hline Reforestation & Space availability & 100 \\
Ocean fertilization & Data availability & $2-450$ \\
Biochar production & Source availability & $30-120$ \\
Weathering & Methods and distribution & 10 \\
Air capture & Operational costs & $94-242$ \\
Seawater extraction & Energy consumption & 50 \\
In situ CCS & Water consumption & $50-100$ \\
\hline
\end{tabular}

In contrast to CCS technologies, and stemming from the realization that combating climate change cannot proceed in the current politico-economical system while dependent on perpetual state-driven financial support (or even charity, as the XPRIZE case attests), the alternative perspective espoused by CDU technologies attempts to offer the missing economic perspective in the form of self-generated positive budgets: CDU technologies are supposed to finance themselves. Following recent initiatives at the European level and in view of the larger picture unfolding globally, we attempt to elucidate on the main points, considerations, and dynamics that drive and formulate modern CDU initiatives as part of the general CCUS front. Finally, in the second part of this review destined for the upcoming issue, we will cast a careful look at all plausible scenarios for transposing CDU projects into Romania, and interrogate the proper conditions for such projects to be founded and developed. 


\section{OVERVIEW OF CARBON DIOXIDE UTILIZATION CONCEPTS}

\subsection{From carbon capture \& storage $(\mathrm{CCS})$ to carbon dioxide utilization $(\mathrm{CDU})$}

Available forecasts on the European energy mix stress that fossil fuels will continue to contribute at higher level than both renewables and nuclear sources, at least in the short and medium terms (European Commission, 2011); this needs to be seen in parallel to the fact that European energy-intensive process industries (e.g. cement, iron and steel, aluminium, pulp and paper, refineries) cannot mitigate inherent emissions due to their requirements for feedstock material conversion (Fig. 2 and 3). The Energy Roadmap 2050 recommended that CCS technologies be applied in $7 \%$ to $32 \%$ of the fossil fuel power generation contribution by 2050 , if the $80 \%$ to $95 \%$ greenhouse gas (GHG) emissions reduction projected target is to be met successfully (European Commission, 2011). On this direction, the 2030 Climate and Energy Policy Framework identified the milestone of at least 40\% GHG reduction level by 2030 (1990 as benchmark reference, 1989 for Romania) (General Secretariat, 2014).

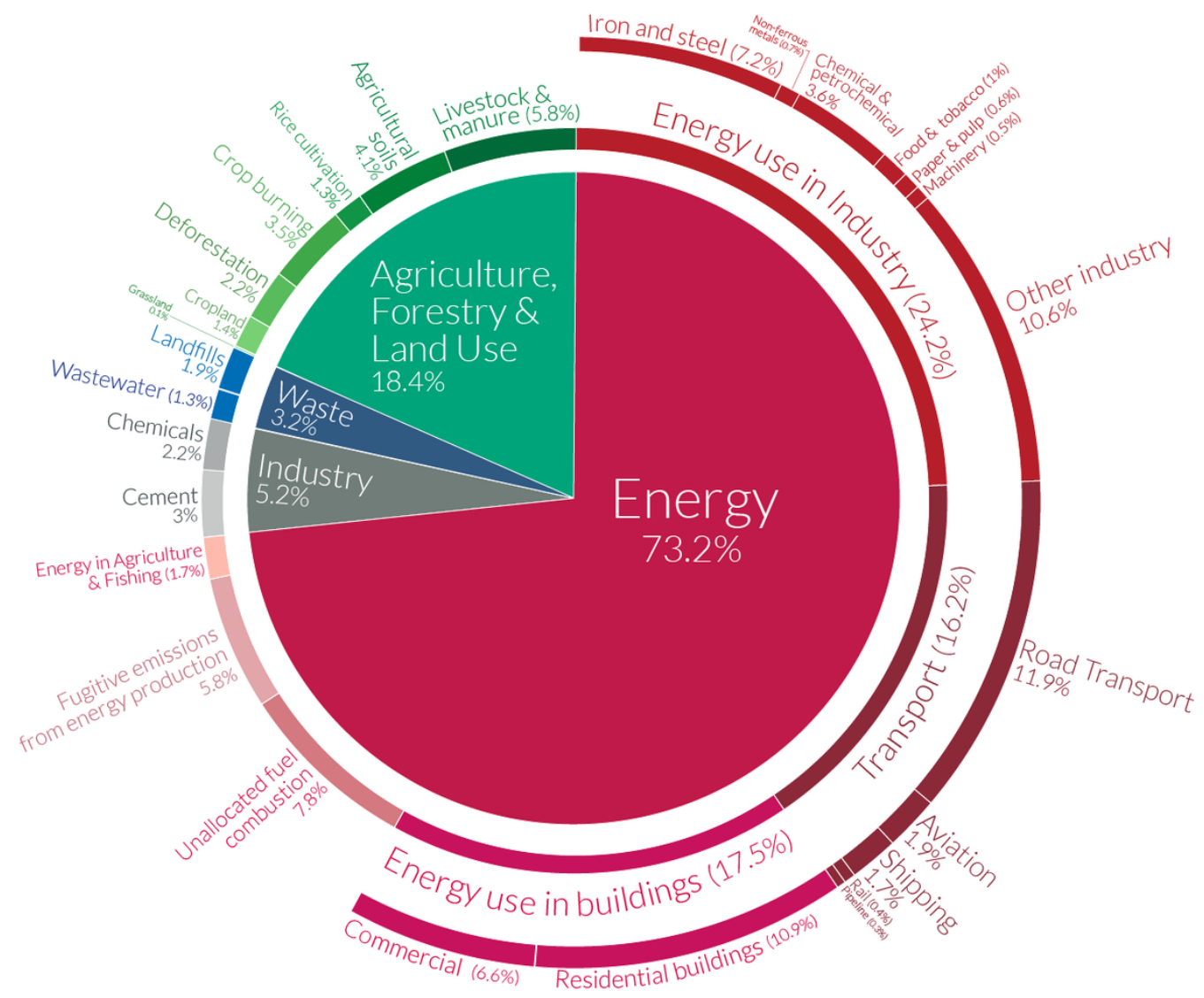

Figure 2. Global greenhouse gas emissions by sector for 2016; total at $49.4 \mathrm{BtCO}_{2}$. (Climate Watch, the World Resources Institute, 2020; Our World in Data, 2020).

To recapitulate, CCUS constitutes a general and encompassing term for capturing anthropogenic $\mathrm{CO}_{2}$ and redirecting it as a carbon molecular carrier for synthesis; in extension, $\mathrm{CDU}$ refers explicitly to such processes of transforming $\mathrm{CO}_{2}$ into a product having commercial value, regardless of its origin (i.e. derived from industrial or natural 
processes). The qualification of CDU as a GHG abatement option comes due to associated emission reductions by preventing or minimizing both the usage of fossil fuels as raw material and the release of net $\mathrm{CO}_{2}$ to the atmosphere. Thus, CDU can also be considered as a standalone set of procedures independent from CCS, although the synergy between the two is self-evident. Another key difference is that CCS is specifically demarcated to the physical neutralization and confinement of $\mathrm{CO}_{2}$, alongside similar practices as enhanced oil recovery (EOR) and industrial processes that employ it as a supercritical solvent - CDU constitutes the chemical transformation of the $\mathrm{CO}_{2}$ molecule instead (Aresta et al., 2013; Styring et al., 2015).

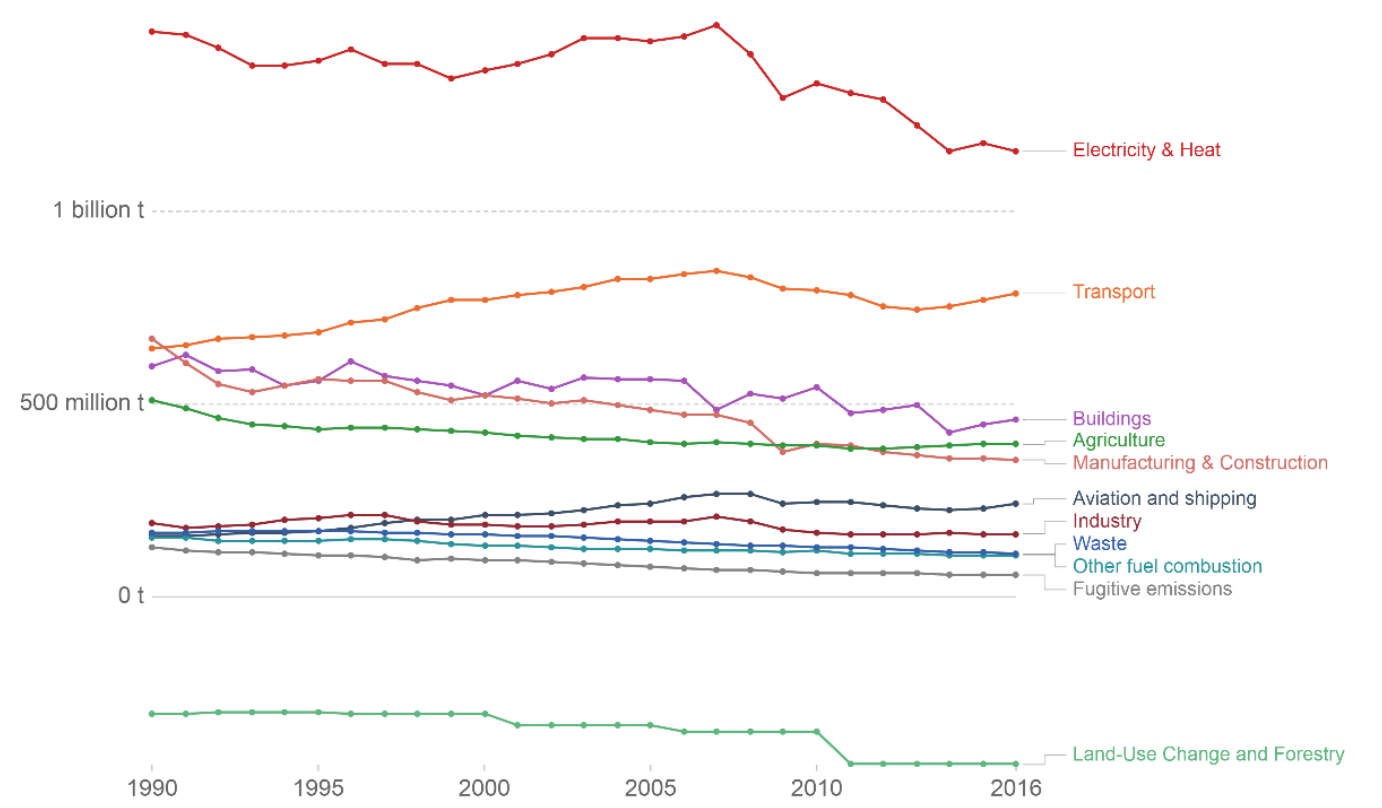

Figure 3. Greenhouse gas emissions by sector over previous 25-year period, European Union-27.

(Climate Watch, the World Resources Institute, 2020; Our World in Data, 2020).

Overall, the added dimension of CDU as an extension of CCS is the potential competitive advantage it can offer to the European industry. In view of this productorientated dimension, however, it is critical to understand that another major difference is the temporary nature of $\mathrm{CO}_{2}$ storage implied by $\mathrm{CDU}$, with the abatement option ending alongside the life cycle of the product itself (Bruhn et al., 2016). Thus, holistic approaches need to be employed for the evaluation of the full CCUS effect on emission abatement, examining both the CCS systemic compartment of carbon capture and the CDU part of transportation and transformation, but also investigating individual product consumption to monitor the possible or eventual re-release of $\mathrm{CO}_{2}$ at the end of the life cycle of each (von der Assen et al., 2014).

The above have been identified in the considerations of the European Union as R\&D priorities in order to secure reaching the climate objectives set for 2050 in a cost-effective manner, also reflected in the Strategic Energy Technologies (SET) Plan (European Commission, $2015^{\mathrm{A}} ; 2015^{\mathrm{B}}$ ), the latter having evolved as a prior research theme in the Integrated Roadmap of the SET Plan (European Commission, 2013 ${ }^{\mathrm{A}}$ ). In this context, CCUS not only pertains to the energy generation and heavy industrial sectors, but also to the policy areas of GHG and climate change, emissions of the transport sector, waste disposal, as well as urban and rural management. 


\subsection{Brief literature review on CDU implementation}

The fundamental concept of $\mathrm{CDU}$, i.e. the $\mathrm{CO}_{2}$-driven synthesis of chemical products, has already been through the first stages of commercialization. Primary feedstock sources have been located on industrial processes that release $\mathrm{CO}_{2}$ as a by-product, e.g. steam reformation of natural gas for hydrogen production or fermentation for ethanol production. The main industrial applications are found in the food, medical, and chemical industries, the latter focusing on urea synthesis, petrochemicals production (plastics), and aerosol production as propellant or blowing agent (Pérez-Fortes et al., 2016 ${ }^{\mathrm{A}}$; $2016^{\mathrm{B}}$; Pérez-Fortes and Tzimas, $2016^{\mathrm{C}}$ ).

Although at present disconnected from the established CDU initiatives, the value chain for captured $\mathrm{CO}_{2}$ obtained via $\mathrm{CCS}$ is largely on the same scale as $\mathrm{CO}_{2}$ collected as industrial by-product, including liquefaction and transportation stages. This disconnection has occurred primarily due to inefficiencies and resulting financial obstacles in CCS targeting large stationary sources (Li et al., 2013). There have also been identified differences between CCS implementations over power plants and general industrial installations, with power plants allowing for post-combustion configuration options, and industrial facilities being better suited for indirect retrofitting layouts (Roddy, 2012). However, installing such retrofitting can be as costly as building new facilities, as is the case for power plants, although overall costs can be significantly lowered by expanding capture and transport networks for variable-size sources of $\mathrm{CO}_{2}$ in the periphery (Rubin et al., 2012). This effectively translates to economies of scale, based on forecasting for expanding such transport networks, and can largely benefit by integrating on-site CCS of natural atmospheric $\mathrm{CO}_{2}$ to shorten the supply chains.

In contrast to CCS facing such critical issues, CDU exhibits a wide range of possibilities by incorporating various Technology Readiness Levels (TRLs) and accommodating diverse products with variable market penetration prospects (Arakawa et al., 2001; Aresta and Dibenedett, 2007; Quadrelli et al., 2011; Peters et al., 2011; Hu et al., 2013). Already established industrial processes, such as catalytic synthesis, can be augmented by even more efficient methods based on electrochemical and photochemical conversion - both in development and thus at low TRL for the time being. Other promising steam-assisted methods include electroreduction in solid oxide electrolyzer cells (SOECs) for the highly efficient production of methanol (Hansen et al., 2012), and co-electrolysis for formate-based products (Dominguez-Ramos et al., 2015). In all such processes, it is underlined that integrating with renewable energy sources for power supply is critical in securing both environmental and economic sustainability, especially if coupled with heat reclamation.

CDU synthesis processes present variable sensitivity to impurities in the $\mathrm{CO}_{2}$ stream, which in turn depend on the quality and cost of the associated CCS methods. This can range from high sensitivity in the case of formic acid synthesis that requires high purity of introduced streams, to very low sensitivity in the case of mineralization, i.e. the conversion of $\mathrm{CO}_{2}$ to its carbonate form. As a rule, high purity is required by $\mathrm{CDU}$ processes that employ sensitive and highly selective catalysts, and result into products with low tolerance to impurities (Markewitz et al., 2012). Consequently, CDU processes that are considered successful from a holistic point of view display adequate tolerance to impurities in captured $\mathrm{CO}_{2}$ streams (Chapman et al., 2015), especially when discussing options for $\mathrm{CO}_{2}$ released as power plant emissions, whose composition will vary based on the degree of oxidation during combustion. In general, $\mathrm{CO}_{2}$ purity is dependent on the applied transport, storage, and environmental requirements and costs - even the strictest standards cannot negate inherent uncertainties (Porter et al., 2015). 
Other interesting options involve biological processes: biogas synthesis via bacterial fermentation, algae production for biofuel synthesis, and bio-mineralization - the latter two options are regarded as complete CCUS processes, since algal growth requires $\mathrm{CO}_{2}$ as feedstock and carbonate is employed as raw material for subsequent chemical synthesis (Pate et al., 2011; Takeshita, 2012). Specifically concerning fuel production, CDU processes classify as Power-to-Liquid and Power-to-Gas when converting electricity into liquid (e.g. methanol) or gaseous fuels (e.g. hydrogen, methane), respectively - by utilizing surplus renewable electricity, renewable energy sources are indirectly introduced into the transport infrastructure (Mesfun et al., 2017; Bellocchi et al., 2019; Crivellari and Cozzani, 2020).

\subsection{Technoeconomic dimensions: CDU for methanol production}

In contribution to the debate on the potential of CDU as a mitigation tool for climate change and the competitiveness of such processes, an assessment of five CDU-compatible products (methanol, formic acid, urea, aggregate for concrete, and polyether carbonate polyol for polyurethanes) was issued in 2016 by the Joint Research Centre (JRC) of the EU Science Hub (Pérez-Fortes et al., 2016 ${ }^{\mathrm{A}}$; 2016 ; Pérez-Fortes and Tzimas, 2016 ${ }^{\mathrm{C}}$ ). The report assessed the technological, economic, and environmental performances for the industrial-scale production of methanol and formic acid from carbon dioxide, both employed as hydrogen carriers and generally as fuels in the transport sector. The study evaluated the net $\mathrm{CO}_{2}$ emission reduction and the potential economic competitiveness of the associated processes compared to conventional synthesis using fossil fuel precursors. Technological, economic and environmental performance indicators were calculated using process system engineering (PSE) approaches; the study boundaries included hydrogen production via electrolyzers, $\mathrm{CO}_{2}$ purification and compression, and the $\mathrm{CDU}$ plant as the physical boundary with all associated energetic and material inputs and outputs. Net production values were employed as the evaluation parameter for the cost of using $\mathrm{CO}_{2}$ as raw material for producing methanol and formic acid, and threshold values were extracted to mark the point where $\mathrm{CO}_{2}$-based processes were rendered financially viable. Penetration scenarios for both products were projected up to 2030 under the assumption of a growing demand in the market.

Overall, the JRC study concluded that depending on specific technoeconomic conditions (i.e. source of feedstock, inflows and costs of energy and feedstock, market price of products), a CDU plant may become directly profitable - not just self-sufficient or sustainable - and contribute accordingly towards emission mitigation. However, the major remark was that the economic viability of a CDU plant depends on the availability of renewable electricity (Fig. 4) - instead of the demand of an associated product - with profitability emerging under auspicious but also realistic conditions.

Methanol synthesis from hydrogen and $\mathrm{CO}_{2}$ is currently under development, with both pilot and demonstration plants installed by various companies worldwide (Doyle, 2020; Mitsui Chemicals Inc., 2009) - formic acid synthesis from the same precursors is still in its infancy. Conventional methanol plants in Europe use natural gas and heavy crude oil as raw materials, producing an average annual output of $450 \mathrm{kt}$ of methanol. Conventional formic acid plants range from 20 to $100 \mathrm{kt}$ output production, with the most common synthesis process for formic acid based on methyl formate hydrolysis (Pérez-Fortes and Tzimas, $2016^{\mathrm{C}}$ ).

Methanol is currently a chemical that can assume an important role as transport fuel, used raw or further transformed into derivatives, such as dimethyl ether or formaldehyde. Currently, methanol synthesis from captured $\mathrm{CO}_{2}$ is at TRL 6 to 7 . The electrolyzer unit is 
the major electricity consumer - according to CDU foundational conditions, it has to be powered by renewables or zero-emission sources. The process is highly efficient in terms of $\mathrm{CO}_{2}$ and $\mathrm{H}_{2}$ conversion: the methanol CDU plant has the potential of achieving up to $77 \%$ emissions reduction compared to conventional plants using natural gas or residual fuel oil as feedstock. However, operating costs can surpass its benefits, with electricity cost being the main negative contributor to its budget. In order to be economically competitive (positive or zero Net Present Value, NPV), univariate and bivariate sensitivity analyses have shown the most important variables to be electricity and methanol market prices. To secure a positive NPV, these will have to formulate as lower than $€ 9 / \mathrm{MWh}$ for electricity and higher than $€ 378 / \mathrm{t}$ for methanol (reference market price, $€ 350 / \mathrm{t}$ ), supported by income from emission mitigation by using $\mathrm{CO}_{2}$ as feedstock higher than $€ 665 / \mathrm{t}$. The bivariate analysis demonstrated that with low electricity costs, the CDU plant can actually absorb the cost of feedstock $\mathrm{CO}_{2}$ - with renewable electricity, methanol can even be sold at a price lower than its current market value of $€ 240 / t$ (Pérez-Fortes and Tzimas, 2016 ${ }^{\mathrm{C}}$ ).

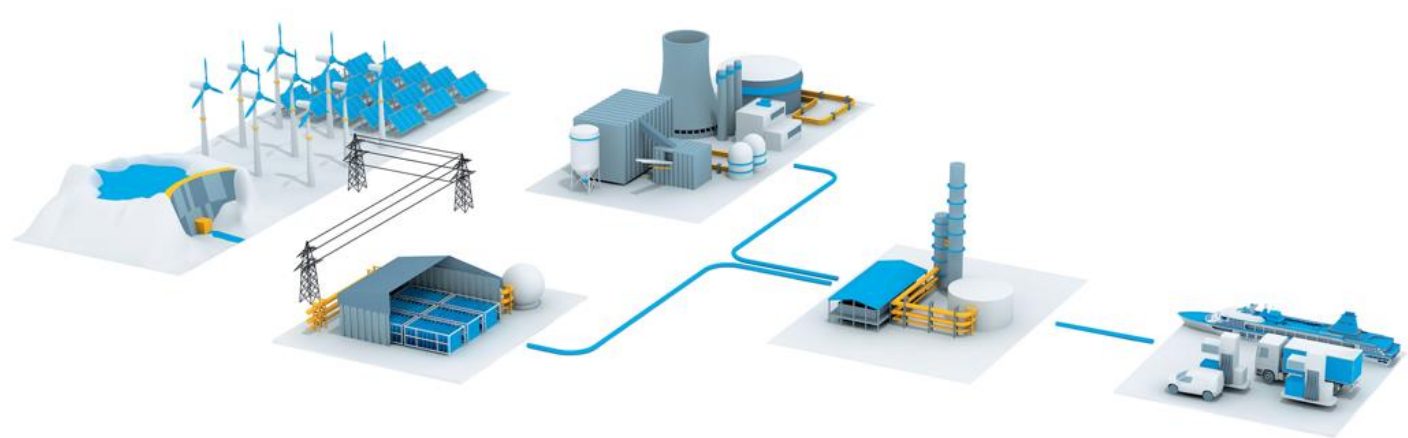

Figure 4. Integrated CDU pathway for methanol production using: (left to right) RES for generating the energy for water electrolysis (e.g. wind, solar, hydro), capturing $\mathrm{CO}_{2}$ from industrial emissions (in situ capture and in situ or ex situ containment), producing green methanol from hydrogen and $\mathrm{CO}_{2}$ in small dedicated modular plants, and finally transportation and distribution for consumption.

Market penetration pathways assumed a methanol yearly demand increase and the coverage of imports, as well as its possible use in the shipping sector, in fuel cells, in stationary applications, in passenger and light commercial vehicles (Fuel Quality Directive). The methanol production in 2016 was 58Mt/yr worldwide; meeting the European yearly demand in 2030 would require 41 to $76 \mathrm{Mt} \mathrm{CO}_{2} / \mathrm{yr}$. This corresponds to a 16 to $31 \mathrm{Mt} \mathrm{CO}_{2} / \mathrm{yr}$ of emissions mitigation to provide the required 28 to $52 \mathrm{Mt} \mathrm{MeOH} / \mathrm{yr}$, also resulting in a decrease on natural gas consumption by 17 to $31 \mathrm{Mt} / \mathrm{yr}$. As comparison, the European Parliamentary Research Service estimates a need of 42 to $71 \mathrm{Mt} \mathrm{MeOH} / \mathrm{yr}$, rising to 69 to $104 \mathrm{Mt} / \mathrm{yr}$ of $\mathrm{CO}_{2}$ as feedstock by 2050 (Pérez-Fortes et al., 2016 ${ }^{\mathrm{B}}$ ).

The JRC gate-to-gate analysis demonstrated that CDU can realistically provide a net contribution to $\mathrm{CO}_{2}$ emissions reduction at plant level. However, neither the context nor the supply chain had been implemented, while $\mathrm{CO}_{2}$ fuels and products had not yet been fully defined in any directive, like the recently revised Renewable Energy and Fuel Quality Directives, which take into account such $\mathrm{CO}_{2}$-synthesized products and fuels. The fundamental conclusions of the report were that there was a need for R\&D in electrolyzers for cost reduction, and a need to combine CDU with renewable energy as electricity input. Different conditions are needed for CDU technologies to reach profitability: lower electricity and steam prices, better plant integration, higher revenues for using $\mathrm{CO}_{2}$ and 
associated products, and intensive R\&D towards state-of-the-art catalysis. Overall, the JRC study provided a favorable evaluation of CDU technologies, both in their economic and ecological dimensions.

\subsection{Technoeconomic dimensions: CDU and hydrogen energy}

As mentioned above, methanol synthesis from $\mathrm{CO}_{2}$ demands hydrogen among its feedstock inputs. Apart from CDU implementations, the global market demand for hydrogen has been steadily growing over the last decade, with key areas of application being both in the transport and the stationary sectors, e.g. for energy generation (IHS Chemical, 2013) - advanced applications have also seen hydrogen replacing kerosene as fuel in aviation (European Commission, 2013 ${ }^{\mathrm{B}}$ ). Most of its bulk production over that period constituted "brown" hydrogen, derived at the overwhelming $96 \%$ from fossil fuels either as main product or by-product. This accounts for $48 \%$ derived from natural gas through steam reformation, $30 \%$ from liquid hydrocarbons, $18 \%$ from coal, and the remaining $4 \%$ as secondary by-product obtained from gasification processes (Kothari et al., 2008; IEA, 2012).

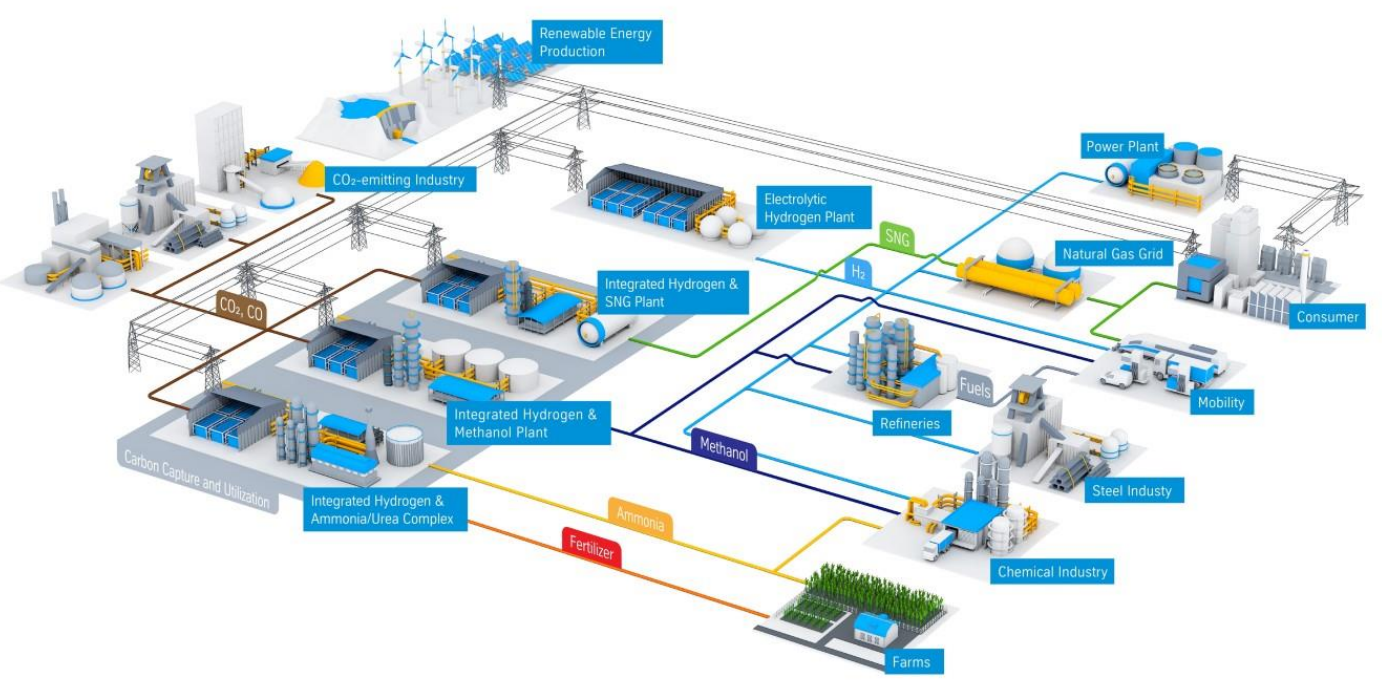

Figure 5. Large-scale integrated CCUS network combining in situ CCS from $\mathrm{CO}_{2}$-emitting industrial plants; energy generation via RES for water electrolysis and hydrogen generation; parallel

CDU processing for specific products (e.g. hydrogen, Synthetic Natural Gas (SNG), methanol, ammonia, fertilizers etc.); transportation and availability to end-users and consumer network.

However, switching to "green" hydrogen generation by carbon-free sources, e.g. biomass gasification or electrolysis powered by renewable or nuclear energy, can significantly reduce carbon emissions (IEA, 2012). Coupled with infrastructure developments in energy storage to tackle the intermittency issues that typically hinder the availability of renewable energy (wind and solar being the most common sources for electricity supply in electrolysis), its addition to the energy mix of nuclear and biomassderived sources can secure hydrogen generation at continuous rates (Langè and Pellegrini, 2013). The primary technology for hydrogen generation is the electrolyzer: alkaline exchange (AEM) and proton exchange membrane (PEM) electrolyzers being the most developed implementations, and the highly efficient but less developed solid oxide electrolyzer cells (SOECs) for steam electrolysis (Redissi and Bouallou, 2013). 
Even more evolved concepts reposition the role of hydrogen as an energy carrier by combining large-scale renewable energy sources (RES) with fuel cell (FC) technology to augment the energy storage capacity of integrated Power-to-Gas installations, where FCs are repurposed to provide auxiliary power on demand to counter intermittency issues by using the electrolysis-derived hydrogen originally produced by RES on peak production (Carton and Olabi, 2010; Gahleitner, 2013; Centi et al., 2013; Mesfun et al., 2017; Bellocchi et al., 2019; Crivellari and Cozzani, 2020). Extending the concept, the requirement of the chemical industry to reduce its dependency on fossil fuels is also addressed by the adoption of CDU processes combined with hydrogen generation as a storage medium for excess off-peak electrical energy, and a means to introduce RES into the chemical production chain (Centi et al., 2013).

Such large-scale integrated implementations (Fig. 5) require centralized hydrogen production and thus the development of additional infrastructure dedicated to its storage and delivery to a variety of end-users (Simoes et al., 2013). Cost reduction and energy efficiency of such distribution systems can - in theory - be achieved by the employment of hydrogen carriers that store hydrogen in some other chemical state rather than as free molecules. Carriers are a unique way to deliver hydrogen by hydriding a chemical compound at the site of production and then dehydriding it at the point of delivery. Potential carriers include metal hydrides, carbonic or other nanostructures, and reversible hydrocarbons or other liquids. This method is still in the early stages of R\&D, and as of yet it has not been fully verified for its energy or cost efficiency. However, one of such proposed carriers, liquid formic acid, has been identified as having a $\mathrm{CO}_{2}$-neutral cycle, with its synthesis from $\mathrm{CO}_{2}$ and hydrogen being fully reversible (Aresta et al., 2014).

The total annual hydrogen production in Europe by the end of 2010 amounted up to 8.269 Mt (92B Nm 3 in gas cubic meters for hydrogen), accounting for $64 \%$ produced by the captive gas industry (ammonia and methanol), $27 \%$ by the by-product industry (ethylene, acetylene, styrene, and coke-oven gas), and $9 \%$ by merchant companies (Maisonnier and Steinberger-Wilckens, 2007). There were 83 installations included in the EU ETS concerning hydrogen and syngas generation, including plants from the chemical and refinery sectors (ECOFYS, 2009). By 2020, this raised to $9.756 \mathrm{Mt}\left(108 \mathrm{~B} \mathrm{Nm}^{3}\right)$ accounting only for merchant hydrogen and purposely produced hydrogen, without hydrogen produced as a by-product (Kakoulaki et al., 2021) - thus up to $13.365 \mathrm{Mt}$ (147B $\mathrm{Nm}^{3}$ ) if the same contribution by the by-product industry is assumed. The majority of hydrogen consumption is associated with two industries: oil refineries with $50 \%$ and ammonia production with $42 \%$ (Maisonnier and Steinberger-Wilckens, 2007). The hydrogen market is rapidly growing due to the recent introduction of regulations in transport fuel desulphurization (IHS Chemical, 2013).

\section{CARBON DIOXIDE UTILIZATION IN EUROPEAN POLICIES}

\subsection{New beginnings - the Paris Agreement}

The Paris Agreement was introduced by the United Nations Framework Convention on Climate Change (UNFCCC) on the $12^{\text {th }}$ of December 2015, which included 196 parties; it was signed by 194 of them and ratified by over 120 states, entering into force on the $4^{\text {th }}$ of November 2016 (UNFCCC, 2015). The Agreement constitutes a legally binding international treaty on climate change and the necessary update to the 1992 General Assembly (UNFCCC, 1992; Maslin, 2020); its goal is to limit global warming to below $2{ }^{\circ} \mathrm{C}$, with the optimal scenario "pursuing efforts" for below $1.5^{\circ} \mathrm{C}$, compared to preindustrial levels (Droege et al., 2016). To achieve this long-term goal, countries aim to 
reach global peaking of GHG emissions as the earliest to achieve a climate neutral world by 2050 . The Paris Agreement is a landmark in climate change multilateralism, as the first time of a binding agreement for all participating nations undertaking such ambitious efforts to combat climate change.

Implementation of the 2015 Paris Agreement requires social and economic transformation based on robust science. The Paris Agreement applies a 5-year cycle of increasingly ambitious climate actions to be carried out by the participating countries, which have to submit plans nationally determined contributions (NDCs) by 2020; in such NDCs, actions are communicated that will reduce GHG emissions to reach the goals set by the Paris Agreement, and that will build adaptive resilience to the impacts of rising temperatures. To frame their efforts, countries may formulate and submit non-mandatory long-term low emission development strategies (LT-LEDS), which set the individual horizons for NDCs, thus placing them into the context of planning and developmental priorities (Fig. 6).

Essentially, the Paris Agreement aims to provide a much needed framework for the financial, technical, and capacity-building support to both developed and developing countries, by placing the first at the lead of financial assistance initiatives towards the latter, while for the first time also encouraging voluntary contributions by third parties. The importance of climate finance is also underlined, since large-scale investments are in critical need both for mitigation and for adaptation, to significantly reduce emissions but also to adapt to the adverse effects and reduce the impacts of a changing climate. The Agreement helps to establish an enveloping technology framework for accelerating development and transfer to all involved participants.

(a) Emissions pathways

(b) Temperature probabilities



Figure 6. IPCC projections of climate profiles of global warming correlated to the level of ambition of NDCs adopted at the international level according to the Paris Agreement. (IPCC, 2021)

The Paris Agreement emphasizes climate-related capacity-building actions for developing countries with the support of partner developed countries by establishing an enhanced transparency framework (ETF). Thus, starting in 2024, all participants have to report on actions taken and progress achieved in climate change mitigation, adaptation measures, and support provided or received according to transparent international review procedures. ETF information will accumulate into the 5-yearly reviews assessing the collective progress towards set goals and helping to formulate subsequent planning.

Within the first years since its implementation, the Paris Agreement has already kindled new low-carbon solutions and markets, helping participating countries to establish 
carbon neutrality targets. Across economic sectors, zero-carbon solutions are becoming competitive (up to $25 \%$ of total emissions), with the trend being especially prevalent in the power and transport sectors. By 2030, a $70 \%$ of global emissions is projected to be represented by competitive zero-carbon solutions.

\subsection{Parallel initiatives and regulatory background}

Even before the ratification of the Agreement, CDU was attracting the attention of policy makers as a viable alternative for motivating local economies with appropriately supportive measures to install economically feasible CDU plants, and for managing and reducing fossil fuel dependence and thus anthropogenic emissions. This variation in local conditions resulted in different motivational drivers, with reports such as the ones from the Global CCS Institute (GCCSI, 2011), the Carbon Sequestration Leadership Forum (CSLF, 2012), and the French Environment and Energy Management Agency (ADEME, 2014) highlighting the potential of existing and future CDU options through their competitive advantages, but without neglecting their limitations in scaled contributions.

In an effort to address such discrepancies resulting from localized variations in feasibility conditions, the European Commission adopted the Energy Union Strategy in February of 2015, with the overall scope of addressing climate change issues and transforming its energy system. In view of the 2050 climate objectives, CCUS developments in the power and industrial sectors were included alongside augmented directives for competitiveness and integration of the European markets, energy efficiency and security, decarbonization, research and innovation. Such directives were outlined in the SET documentation "Towards and Integrated Strategic Energy Technology (SET) Plan: Accelerating the European Energy System Transformation" (European Commission, $\left.2015^{\mathrm{B}}\right)$. Although at the time of issue of SET, CDU fuels and products were not yet fully catalogued, its implementation - especially the directives outlined in the Emissions Trading System and the Innovation Fund, the amendment to the Renewable Energy Directive, and the Fuel Quality Directive with regard to CDU for transport purposes - had a positive effect on CDU initiatives in Europe.

The Horizon 2020 Programme, the main arm for Research and Innovation as outlined in SET 2015, launched several calls relevant to CCUS. The 2015-2016 work programme, under the "Secure, Clean and Efficient Energy" thematic, called for CDU for the process industry and aimed for technology demonstrations in relevant scales and environments (TRLs 6 to 7). The Industry 2020 in the Circular Economy (H2020-IND-CE2016-17) Programme for Sustainable Process Industry through Resource and Energy Efficiency (LC-SPIRE-08) supported the CDU for added-value chemicals and the synthesis of cost-effective materials for Power-to-Chemical technologies. Consecutive EC Horizon Prize awards of EUR 1.5M were given to innovative CDU-derived products, which had to demonstrate significant reduction in carbon emissions while overcoming technical, commercial and financial commercialization barriers.

\subsection{CCUS in the context of the Paris Agreement}

However impressive and auspicious the reception of the Paris Agreement had been, analyses of initial commitments of most of the participating countries have revealed they were not on course to truly meet the objectives set in 2015. As reflected on their NDCs, only three participants (Canada, Norway, and Saudi Arabia) declared CCUS as prioritized focus area. Even the initial NDC plan submitted by the USA under the Obama Administration did not explicitly mention CCUS. If the technology is to play a meaningful 
role in future climate mitigation, it is disconcerting the level of deferral CCUS deployment has been facing. At the end of 2019, the Global CCS Institute (GCCSI) reported the status of 51 large-scale CCUS facilities globally: 19 in operation, 4 under construction, and 28 in various stages of development. Overall, the existing facilities have an estimated capture capacity of around $96 \mathrm{MtCO}_{2} / \mathrm{yr}$. Most aspects of CCUS technology have been commercially demonstrated; dedicated transport pipelines and natural gas separation plants have been operating for decades. The verdict is that additional efforts are needed to reduce costs and to scale-up without governmental support. Apart from the 19 operating facilities, GCCSI estimates that at least 2500 such CCUS facilities must be put into operation to equalize modeled need and commercial requirements. CCUS remains a costly and complicated technology, though many countries and companies are devoting significant resources to reducing costs and making it more commercially viable. One such example is the Carbon Storage Assurance Facility Enterprise program of the U.S. Department of Energy, which has the goal of supporting the development of large-scale integrated CCUS projects throughout the USA over the running decade - complex technologies typically take decades to reach full commercialization. The final commercial scale of CCUS remains uncertain, but efforts must continue to ensure the technology has a legitimate chance to flourish. This can only be achieved by carefully implemented policy initiatives.

In the GCCSI 2019 status report, project-supportive policy levers that included grants, tax incentives, and $\mathrm{CO}_{2}$ enhanced oil recovery were identified - the report also identified emission credits as a valuable policy tool, which played a vital role in the sustainable development of 7 projects worldwide. CCUS incentives have to constitute essential mechanisms of the framework of the Agreement in order to tackle emissions within the projected timeframe. The mere existence of the Paris Agreement does not necessarily guarantee success if its tenets remain only on paper as wishful thinking - the Kyoto Protocol provides for relevant admonition: the Kyoto Clean Development Mechanism had approved CCUS methodologies, yet no projects were ever developed.

Prior to the ongoing COVID-19 pandemic, the conclusion of the Paris Agreement regulatory negotiations was scheduled for November $2021\left(26^{\text {th }}\right.$ Conference of the Parties, 2021 UN Climate Change Conference, COP26, Glasgow, UK), which at present has been postponed (Obergassel et al., 2020). Fortunately, since the negotiations on the Agreement are still in flux, the international community has the opportunity to reconsider and lend additional support to CCUS projects.

\section{CONCLUSIONS}

In the first installment of this review on CCUS technologies - the set of proposed technological solutions that seek to trap anthropogenic carbon dioxide before its release into the atmosphere - we have focused on elucidating on the distinction between CCS and CDU, the two diverging paths of CCUS. CDU refers explicitly to processes of transforming carbon dioxide into a product of commercial value, adding the critical financial dimension that CCS is lacking, and thus promising to render CDU processes economically viable - whereas CCS can function solely under the continuous financial support by the private or public enterprise in the form of policies and subsidies. Our analysis continued with providing examples of such successful CDU implementations, in the form of CDU-based production of methanol and hydrogen in various industrial or experimental processes, focusing on both their economic and technological dimensions. Finally, we examined the current political background that affects the future development of such processes, focusing on both European-level initiatives and the recently ratified Paris Agreement, which came with the promise of revising and amending the shortcomings 
of the Kyoto Protocols. Hailed as the definitive political solution to the ongoing global ecological crisis, the Paris Agreement still met with unveiled animosity from certain financial and national interest groups, while most participants presented vague or timid NDCs (nationally determined contributions) as their 5-year policy projections - these will certainly have to be amended after initial assessments. The greatest misgiving, however, lies in failing to disentangle CDU from CCS, keeping both under the umbrella of CCUS, and thus hindering the momentum inherent in CDU processes regarding financial viability and competitiveness. Hopefully, this will be rectified in the near future, after the hiatus forced by the COVID-19 pandemic. In the next installment of this review, we will delve deeper into CDU technologies that can be readily implemented in Romania, and the advantages that they hold to offer to our national economy and ecology.

Acknowledgements: The authors would like to acknowledge the financial support by the Ministry of Research, Innovation, and Digitization of Romania through the National Plan of Research and Development, Project PN 19-11-02-01; and by the Executive Agency for Higher Education, Research, Development \& Innovation Funding (UEFISCDI), through Project PN-III-P2-2.1-PED2019-1894, Contract no. 460PED/2020.

Funding: Projects PN 19-11-02-01 and PN-III-P2-2.1-PED-2019-1894 (460PED/2020).

Author contributions: Both authors claim equal contributions to this work.

Conflict of Interest Statement: The authors declare no conflict of interest regarding this work.

\section{REFERENCES}

ADEME, 2014. Chemical conversion of $\mathrm{CO}_{2}$. Quantification of energy and environmental benefits and economic evaluation of three chemical routes.

Arakawa, H., Aresta, M., Armor, J. N., Barteau, M. A., Beckman, E. J., Bell, A. T., Bercaw, J. E., Creutz, C., Dinjus, E., Dixon, D. A., Domen, K., 2001. Catalysis research of relevance to carbon management: progress, challenges, and opportunities. Chem. Rev. 101(4), 953-96.

Aresta, M., Dibenedetto, A., 2007. Utilisation of $\mathrm{CO}_{2}$ as a chemical feedstock: Opportunities and challenges. Dalt. Trans., 2975-2992.

Aresta, M., Dibenedetto, A., Angelini, A., 2013. The changing paradigm in $\mathrm{CO}_{2}$ utilization, J. $\mathrm{CO}_{2}$ Util. 3-4, 65-73.

Aresta, M., Dibenedetto, A., Angelini, A., 2014. Catalysis for the valorization of exhaust carbon: From $\mathrm{CO}_{2}$ to chemicals, materials, and fuels. Technological use of $\mathrm{CO}_{2}$. ACS Chem. Rev., 114(3), 1709-42.

Bellocchi, S., De Falco, M., Gambini, M., Manno, M., Stilo, T., Vellini, M., 2019. Opportunities for power-to-Gas and Power-to-liquid in $\mathrm{CO}_{2}$-reduced energy scenarios: The Italian case. Energy, 175, 847-61.

Bernstein, L., Bosch, P., Canziani, O., Chen, Z., Christ, R., Riahi, K., 2008. IPCC, 2007: climate change 2007: synthesis report.

Bruhn, T., Naims, H., Olfe-Krautlein, B., 2016. Separating the debate on $\mathrm{CO}_{2}$ utilisation from carbon capture and storage. Environ. Sci. Policy 60, 38-40.

Carton, J., Olabi, A., 2010. Wind/hydrogen hybrid systems: Opportunity for Ireland's wind resource to provide consistent sustainable energy supply. Energy 35, 4536-4544.

Centi, G., Quadrelli, E. A., Perathoner, S., 2013. Catalysis for $\mathrm{CO}_{2}$ conversion: a key technology for rapid introduction of renewable energy in the value chain of chemical industries. Energy Environ. Sci., 6, 1711-31.

Chapman, A. M., Keyworth, C., Kember, M. R., Lennox, A. J. J., Williams, C. K., 2015. Adding value to power station captured $\mathrm{CO}_{2}$ : tolerant $\mathrm{Zn}$ and $\mathrm{Mg}$ homogeneous catalysts for polycarbonate polyol production. ACS Catal., 5(3), 1581-8. 
Climate Watch, the World Resources Institute, 2020. Retrieved: 30/04/2010. https://www.wri.org/

Crivellari, A., Cozzani, V., 2020. Offshore renewable energy exploitation strategies in remote areas by power-to-gas and power-to-liquid conversion. Int. J. Hydrog. Energy 45(4), 2936-2953.

CSLF, 2012. $\mathrm{CO}_{2}$ utilisation options - Phase $1 \&$ Phase 2 Reports.

Dominguez-Ramos, A., Singh, B., Zhang, X., Hertwich, E. G., Irabien, A., 2015. Global warming footprint of the electrochemical reduction of carbon dioxide to formate. J. Clean. Prod., 104, 148-55.

Doyle, A., 2020. CRI successfully demonstrates chemical storage with renewable methanol. The Chemical Engineer, published on 21/07/2020, retrieved on 02/05/2021: https://www. thechemicalengineer.com/news/cri-successfully-demonstrates-chemical-storage-with-renewablemethanol/

Droege, S., Van Asselt, H., Das, K., Mehling, M., 2016. The trade system and climate action: ways forward under the Paris Agreement. SCJ Int'l L. \& Bus. 13, 195.

Ecofys, Fraunhoffer Institute for Systems and Innovation Research, and Öko-Institut, 2019. Methodology for the free allocation of emission allowances in the EU ETS post 2012 - Sector report for the chemical industry.

Eggleston, H. S., Buendia, L., Miwa, K., Ngara, T., Tanabe, K., 2006. 2006 IPCC guidelines for national greenhouse gas inventories.

European Commission, 2011. Energy Roadmap 2050. Impact assessment and scenario analysis.

European Commission, 2013 ${ }^{\mathrm{A}}$. Towards an Integrated Strategic Energy Technology (SET) Plan: Research and Innovation Challenges and Needs of the EU Energy System.

European Commission, 2013 ${ }^{\mathrm{B}}$. $\mathrm{H}_{2}$ Aircraft - CRYOPLANE and the future of flight.

European Commission, 2015 . Energy Union Package - A Framework Strategy for a Resilient Energy Union with a Forward-Looking Climate Change Policy.

European Commission, 2015 ${ }^{\mathrm{B}}$. Towards an Integrated Strategic Energy Technology (SET) Plan: Accelerating the European Energy System Transformation.

Gahleitner, G., 2013. Hydrogen from renewable electricity: An international review for power-togas pilot plants for stationary applications. Int. J. Hydrogen Energy 38, 2039-61.

GCCSI \& PB, 2011. Accelerating the uptake of CCS: industrial use of captured carbon dioxide.

General Secretariat of the Council, 2014. Conclusions on 2030 climate and energy policy framework.

Hansen, J. B., Dybkjær, I., Pedersen, C. F., 2012. SOEC enabled Methanol Synthesis, in $10^{\text {th }}$ European SOFC Forum 2012, A1105.

Hossenfelder, S., 2021. All you need to know about Elon Musk's Carbon Capture Prize. YouTube Personal Channel of Sabine Hossenfelder, retrieved on 20/04/2021: https://www.youtube.com/watch?v= GmWpFCjh0Fk\&list=WL\&index=5\&ab_channel=SabineHossenfelder.

Hu, B., Guild, C., Suib, S. L., 2013. Thermal, electrochemical, and photochemical conversion of $\mathrm{CO}_{2}$ to fuels and value-added products. J. $\mathrm{CO}_{2}$ Util. 1, 18-27.

IEA (International Energy Agency), 2012. Energy technology perspectives 2012: Pathways to a clean energy system. France.

IHS Chemical, 2013. Hydrogen - Abstract from the report Chemicals Economic Handbook.

IPCC, 2021. The Intergovernmental Panel on Climate Change. https://www.ipcc.ch/

Kakoulaki, G., Kougias, I., Taylor, N., Dolci, F., Moya, J., Jäger-Waldau, A., 2021. Green hydrogen in Europe - A regional assessment: Substituting existing production with electrolysis powered by renewables. Energy Convers. Manag. 228, 113649.

Kothari, R., Buddhi, D., Sawhney, R. L., 2008. Comparison of environmental and economic aspects of various hydrogen production methods. Renew. Sustain. Energy Rev. 12(2), 553-63.

Langè, S., Pellegrini, L. A., 2013. Sustainable combined production of hydrogen and energy from biomass in Malaysia. Chem. Eng. Trans. 32, 607-12.

Li, B., Duan, Y., Luebke, D., Morreale, B., 2013, Advances in $\mathrm{CO}_{2}$ capture technology: A patent review. Appl. Energy 102, 1439-47.

Maisonnier, G. Steinberger-Wilckens, R., 2007. Deliverable 2.1 and 2.1.a 'European Hydrogen Infrastructure Atlas' and 'Industrial Excess Hydrogen Analysis'- Part II: Industrial surplus hydrogen and markets and production.

Markewitz, P., Kuckshinrichs, W., Leitner, W., Linssen, J., Zapp, P., Bongartz, R., Schreiber, A., Müller, T. E., 2012. Worldwide innovations in the development of carbon capture technologies 
and the utilization of $\mathrm{CO}_{2}$. Energy Environ. Sci. 5(6), 7281-305.

Maslin, M. A., 2020. The road from Rio to Glasgow: a short history of the climate change negotiations. Scott. Geogr. J. 136(1-4), 5-12.

Mesfun, S., Sanchez, D. L., Leduc, S., Wetterlund, E., Lundgren, J., Biberacher, M., Kraxner, F., 2017. Power-to-gas and power-to-liquid for managing renewable electricity intermittency in the Alpine Region. Renew. Energy 107, 361-72.

Mitsui Chemicals Inc., 2009. CSR Report.

Musk Foundation, 2021. XPRIZE Carbon Removal competition website, retrieved on 20/04/2021: https://www.xprize.org/prizes/elonmusk.

Obergassel, W., Hermwille, L., Oberthür, S., 2020. Harnessing international climate governance to drive a sustainable recovery from the COVID-19 pandemic. Clim. Policy 1-9.

Our World in Data, 2020. Retrieved: 30/04/2010. https://ourworldindata.org/emissions-by-sector

Pachauri, R. K., Reisinger, A., 2007. IPCC fourth assessment report. IPCC, Geneva.

Pate, R., Klise, G., Wu, B., 2011. Resource demand implications for US algae biofuels production scale-up. Appl. Energy 88(10), 3377-88.

Pérez-Fortes, M., Schöneberger, J. C., Boulamanti, A., Tzimas, E., 2016 ${ }^{\text {A }}$ Methanol synthesis using captured $\mathrm{CO}_{2}$ as raw material: Techno-economic and environmental assessment. Appl. Energy $161,718-32$.

Pérez-Fortes, M., Schöneberger, J.C., Boulamanti, A., Harrison, G., Tzimas, E., 2016 ${ }^{\mathrm{B}}$. Formic acid synthesis using $\mathrm{CO}_{2}$ as raw material: Techno-economic and environmental evaluation and market potential. Int. J. Hydrog. Energy 41(37), 16444-62.

Pérez-Fortes, M., Tzimas, E., 2016 ${ }^{\mathrm{C}}$. Techno-economic and environmental evaluation of $\mathrm{CO}_{2}$ utilisation for fuel production. Synthesis of methanol and formic acid. JRC Science for Policy Report, EUR 27629 EN, doi: 10.2790/809992.

Peters, M., Köhler, B., Kuckshinrichs, W., Leitner, W., Markewitz, P., Müller, T. E., 2011. Chemical technologies for exploiting and recycling carbon dioxide into the value chain. ChemSusChem 4(9), 1216-40.

Porter, R. T., Fairweather, M., Pourkashanian, M., Woolley, R. M., 2015. The range and level of impurities in $\mathrm{CO}_{2}$ streams from different carbon capture sources. Int. J. Greenh. Gas Control 36, 161-74.

Quadrelli, E. A., Centi, G., Duplan, J. L., Perathoner, S., 2011. Carbon dioxide recycling: emerging large-scale technologies with industrial potential. ChemSusChem 4(9), 1194-215.

Rao, S., Chandur, S., 2021. Moving the topic of climate change from politics to economics. Theories of Change: Change Leadership Tools, Models and Applications for Investing in Sustainable Development, 487-500.

Redissi, Y., Bouallou, C., 2013. Valorization of carbon dioxide by co-electrolysis of $\mathrm{CO}_{2} / \mathrm{H}_{2} \mathrm{O}$ at high temperature for syngas production. Energy Proc. 37, 6667-78.

Roddy, D. J., 2012. Development of $\mathrm{CO}_{2}$ network for industrial emissions. J. $\mathrm{CO}_{2}$ Util. 91, 459-65.

Rubin, E., Mantripragada, H., Marks, A., Versteeg, P., Kitchin, J., 2012. The outlook for improved carbon capture technology. Prog. Energy Combust. Sci. 38(5), 630-71.

Simoes, S., Nijs, W., Ruiz, P., Sgobbi, A., Radu, D., Bolat, P., Thiel, C., Peteves, S., 2013. The JRC-EU-TIMES model. Assessing the long-term role of the SET Plan. Publications Office of the European Union, Luxembourg.

Styring, P., Quadrelli, E. A., Armstrong, K., 2015. Carbon dioxide utilisation: Closing the carbon cycle. $1^{\text {st }}$ ed., Elsevier.

Takeshita, T., 2012. Assessing the co-benefits of $\mathrm{CO}_{2}$ mitigation on air pollutants emissions from road vehicles. Appl. Energy 97, 225-237.

UNFCCC, 1992. United Nations Framework Convention on Climate Change. New York: United Nations, General Assembly.

UNFCCC, 2015. Paris Agreement to the United Nations Framework Convention on Climate Change, Dec. 12, 2015, T.I.A.S. No. 16-1104.

von der Assen, N., Voll, P., Peters, M., Bardow, A., 2014. Life cycle assessment of $\mathrm{CO}_{2}$ capture and utilisation: a tutorial review. Chem. Soc. Rev. 43, 7982-94. 